\title{
Calpain Immunoreactivity and Morphological Damage in Chinchilla Inner Ears after Carboplatin
}

\author{
Da lian Ding, Sandra L. McFadden, and Richard J. SAlvi \\ Center for Hearing and Deafness, University of Buffalo, Buffalo, NY 14214, USA
}

Received: 8 January 2001; Accepted: 25 June 2001; Online publication: 31 August 2001

\begin{abstract}
Carboplatin produces an unusual pattern of damage in the chinchilla inner ear, characterized by early destruction of type I afferent fibers and preferential loss of type I hair cells in the vestibular end organs and inner hair cells (IHCs) in the cochlea. In the present study, we investigated a potential role of calpains, a family of calcium-activated proteases, in carboplatin ototoxicity. Chinchillas received carboplatin $(100 \mathrm{mg} / \mathrm{kg} \mathrm{IP})$ and were sacrificed 12, 24, 48, or 72 $\mathrm{h}$ later for morphological evaluation or immunocytochemistry. Nerve fibers and myelin were the initial sites of increased calpain immunoreactivity (IR) and morphological damage. At $12 \mathrm{~h}$, granular immunoreactive puncta were present within nerve fibers and their myelin sheaths in the spiral ganglion. In the habenula perforata, dense reaction product was present in large vacuoles in the myelin surrounding the nerve fibers. At $24 \mathrm{~h}$, nerve fibers and myelin were destroyed in the habenula, and those in the spiral ganglion showed increased calpain IR and morphological damage. At $72 \mathrm{~h}$, nerve fibers and myelin were completely destroyed. Calpain IR was not a prominent feature of IHCs, type I vestibular hair cells, or ganglion cells at any time after carboplatin. The results show a correlation between calpain IR and carboplatininduced axon and myelin degeneration. We propose that calpain-induced axonopathy and myelinopathy are primary features of carboplatin ototoxicity in chinchilla.
\end{abstract}

Keywords: carboplatin, myelinopathy, axonopathy, calpain, ototoxicity, myelin

Correspondence to: Sandra L. McFadden, Ph.D. • Center for Hearing and Deafness $\bullet 215$ Parker Hall $\bullet$ University of Buffalo $\bullet$ Buffalo, NY 14214. Telephone: (716) 829-2001 ext. 13; fax: (716) 829-2980; email: mcfadden@buffalo.edu

\section{INTRODUCTION}

The antineoplastic activity of platinum-based compounds such as cisplatin and carboplatin, a secondgeneration cisplatin analog, makes them effective in the treatment of various types of cancers. However, they can be cytotoxic to many normal tissues as well. Severe toxic side effects, which can include peripheral neuropathy and cumulative and irreversible ototoxicity, are dose-limiting factors in their clinical use (Piccart et al. 1990; Schweitzer 1993; Go and Adjei 1999).

The effects of carboplatin on inner ear morphology and function have been well-characterized in the chinchilla (Takeno et al. 1994a, b; Wake et al. 1994; Mount et al. 1995; Trautwein et al. 1996; Ding et al. 1997; Hofstetter et al. 1997a, b, Ding et al. 1999b). The initial targets of carboplatin are the type I afferent fibers of vestibular ganglion neurons, which innervate type I hair cells in the vestibular end organs, and those of spiral ganglion neurons, which innervate inner hair cells (IHCs) in the cochlea. Sensory cell damage occurs subsequent to neural damage. In the vestibular end organs, type I hair cells are more vulnerable than type II hair cells; in the cochlea, IHCs are more vulnerable than outer hair cells (OHCs). At low doses, carboplatin preferentially destroys IHCs throughout the cochlea, leaving OHCs morphologically and functionally intact. At high doses, carboplatin destroys OHCs as well as IHCs, following a typical base-to-apex gradient of loss.

Cisplatin and carboplatin are believed to act by initiating processes leading to apoptotic and/or necrotic cell death. Both drugs bind to nucleophilic sites in DNA, forming crosslinks (primarily intrastrand links at adjacent $\mathrm{N}^{7}$-guanine sites) that distort the DNA molecule and facilitate the binding of certain proteins 
(Reedijk 1999). The subsequent subcellular processes that culminate in cell death are poorly understood. Aggarwal (1993) has suggested that uncoupling of oxidative phosphorylation and subsequent efflux of calcium $\left(\mathrm{Ca}^{2+}\right)$ from mitochondria are important steps in the process. In vitro studies have shown that cisplatin induces massive release of $\mathrm{Ca}^{2+}$ from mitochondria of liver and kidney cells (Gemba et al. 1987; Aggarwal 1993). In previous studies with carboplatin-treated chinchillas, we observed rapid disruption of mitochondria in vestibular hair cells and the chalices beneath them (Ding et al. 1997) and increased activity of $\mathrm{Ca}^{2+}-$ ATPase in IHCs (Ding et al. 1999a).

One potential consequence of mitochondrial disruption and increased levels of $\mathrm{Ca}^{2+}$ is activation of calpains, a family of cysteine proteases that have been implicated in both cell death and synaptic repair processes (Bartus et al. 1995; Faddis et al. 1997; Stracher 1997; Lee et al. 2000; Yamashima 2000). Calpain has been shown to play a role in hair cell death following acoustic overexposure (Wang et al. 1999), and it is plausible that it contributes to carboplatin ototoxicity as well. The purpose of the present study was to determine if carboplatin damage in the chinchilla inner ear is associated with calpain immunolabeling and, if so, to determine the location and time course of calpain immunoreactivity (IR).

\section{MATERIALS AND METHODS}

\section{Subjects}

All procedures involving animals were approved by the University of Buffalo Institutional Animal Care and Use Committee (Protocol \#HER05080N). Healthy adult chinchillas $(N=30 ; 520-639 \mathrm{~g})$ served as subjects. Twenty-seven animals received a single injection of carboplatin (Bristol-Myers Squibb, Princeton, NJ, USA; $100 \mathrm{mg} / \mathrm{kg} \mathrm{IP}$ ) and were sacrificed at 24, 48, or $72 \mathrm{~h}$ postcarboplatin for morphological evaluation of hair cells and nerve fibers ( 5 animals/group) or at 12, 24,48 , or 72 h postcarboplatin for calpain immunocytochemistry (3 animals/group). Two untreated control animals were also evaluated for calpain IR. Additionally, four adult mice were used for Western blot analysis of the calpain antibody (see below).

\section{Fixation and dissection}

Chinchillas were deeply anesthetized (sodium pentobarbital, $100 \mathrm{mg} / \mathrm{kg}$, IP or $\mathrm{CO}_{2}$ ) and either perfused intracardially with fixative or decapitated. The osseous bullae were quickly removed, and openings were made in the cochlear apex, round window, and oval window. A pipette was used to perfuse $2.5 \%$ glutaraldehyde in
$0.1 \mathrm{M}$ phosphate buffer ( $\mathrm{pH} 7.2$ ) through the oval window. Specimens were immersed in fixative $(2.5 \%$ glutaraldehyde for morphological evaluation, $4 \%$ paraformaldehyde for calpain immunolabeling) for 4 $\mathrm{h}$ at $4^{\circ} \mathrm{C}$, then microdissected to remove the organ of Corti, spiral ganglion, saccule, utricle, the three cristae of the semicircular canal, superior vestibular ganglion, and posterior vestibular ganglion.

\section{Morphological procedures}

Cochleas of 15 animals were processed for counting hair cells and nerve fibers in the habenula perforata of the cochlea. For hair cell counts, cochleas were transferred from fixative to phosphate-buffered saline ( $\mathrm{pH} 7.4$ ), dissected into apical, middle, and basal turn segments, and stained in Harris' hematoxylin solution. Stained segments were whole-mounted in glycerin on glass slides and examined using a light microscope (400X magnification). The numbers of IHCs and OHCs were counted in successive $0.24 \mathrm{~mm}$ segments along the organ of Corti, beginning at the apex. The percent of hair cells missing was determined by comparing hair cell counts to lab standards for normal young chinchillas. For nerve fiber counts, fixed cochleas were decalcified (Decal, Baxter Scientific Products, Deerfield, IL, USA) and embedded in Epon 812 resin. Serial sections (3 $\mu \mathrm{m}$ thick) were made parallel to the modiolar axis, stained with toluidine blue, and examined under the light microscope. The average number of fibers per habenula was determined for normal chinchillas and chinchillas sacrificed 24, 48, or $72 \mathrm{~h}$ postcarboplatin. Averages were based on counts of nerve fibers in habenulae in the middle cochlear turn (20 habenulae per group). It was not possible to reliably distinguish fiber type in our material; thus, fiber counts may include type I afferent, type II afferent, and efferent fibers.

Cochleas of 15 animals were prepared for electron microscopic evaluation. The cochlear and vestibular sensory epithelia were immersed in $2 \%$ osmium tetroxide in $0.1 \mathrm{M}$ phosphate buffer for $2 \mathrm{~h}$ at $4^{\circ} \mathrm{C}$, dehydrated in an ascending ethanol series to $100 \%$, and embedded in Epon 812. Ultrathin sections $(70 \mathrm{~nm})$ were collected on thin-bar nickel grids, stained with uranyl acetate, and examined with an electron microscope.

\section{Calpain immunocytochemistry}

Samples were rinsed with PBS and incubated in $0.3 \%$ $\mathrm{H}_{2} \mathrm{O}_{2}$ for $30 \mathrm{~min}$, then incubated in Triton X-100 $(0.3 \%)$ and normal horse serum $(10 \%)$ in PBS for $60 \mathrm{~min}$. Tissues were incubated overnight in mouse anticalpain small subunit monoclonal antibody (Chemicon International, Temecula, CA, USA). Western blot analysis of mouse brain tissue verified that 
the antibody labeled the small subunit, with expression increasing substantially after $4 \mathrm{~h}$ of anoxia, a condition known to induce calpain activation (Yamashima 2000). In addition to prominent bands corresponding to the small regulatory subunit, a faint band appeared at approximately $110 \mathrm{kDa}$, corresponding to the nondissociated (inactive) heterodimer formed by the $30 \mathrm{kDa}$ regulatory unit and the larger $80 \mathrm{kDa}$ enzymatic subunit of calpain. There was little or no difference between normal and anoxic brain tissue in the intensity of the $110 \mathrm{kDa}$ band. Because the small subunit is common to all calpains, it is not possible to specify the particular calpain(s) labeled in our samples.

Samples were rinsed in PBS, incubated in biotinconjugated, horse-antimouse IgG (1:100) for $60 \mathrm{~min}$, rinsed again, and then processed according to instructions of the ABC kit (Vector, Burlingame, CA, USA ). Samples were subsequently incubated in $2.5 \%$ diaminobenzidine containing $3 \% \mathrm{H}_{2} \mathrm{O}_{2}$ fixed for $2 \mathrm{~h}$ in $1 \%$ osmium tetroxide, washed in PBS, dehydrated in an ascending ethanol series, cleared in propylene oxide, infiltrated overnight in 1:1 propylene oxide and Polybed 812 resin, then embedded in Polybed 812 resin. Ultrathin sections $(70 \mathrm{~nm})$ were observed using a transmission electron microscope without further metal staining. As a control, several pieces of the basilar membrane were incubated with medium lacking either the first or the second antibody and then processed through all of the other steps.

\section{RESULTS}

\section{Calpain immunoreactivity in normal ears}

Three normal ears were processed for calpain immunolabeling. In these ears, hair cells (Fig. 1A), Schwann cells, nerve fibers, and myelin sheaths (Fig. 1B), and spiral ganglion cells (Fig. 1C) appeared morphologically normal. Calpain IR was absent from the IHCs and their supporting cells. A small number of immunoreactive puncta were observed in the myelin surrounding nerve fibers in the habenula perforata (Fig. $1 B$ ) and in the myelin surrounding some type I neurons in the spiral ganglion (Fig. 1C). As shown in Figure 1, the sparse reaction product in normal ears consisted of fine granules of various size and uniform darkness that could represent "noise" in the immunostaining signal or the presence of nondissociated (inactive) calpain.

\section{Calpain immunoreactivity and morphological damage in the cochlea}

Nerve fibers and their myelin sheaths were prominent sites of carboplatin-induced morphological damage and calpain IR in the cochlea at $12 \mathrm{~h}$ postcarboplatin (Fig. 2). Numerous small immunoreactive puncta of uniform size and density were observed in the cytoplasm of nerve fibers in the spiral ganglion, and immunoreactive puncta of more variable size and density were present in their myelin sheaths and within intramyelinic vacuoles (Fig. 2A). No calpain IR was visible in the cytoplasm of any cochlear ganglion cell. Myelin splitting and edema without calpain IR was observed in some ganglion cells (Fig. 2A). For both nerve fibers and spiral ganglion neurons, the innermost layers of myelin tended to be the initial sites of splitting and vacuolization.

The strongest calpain IR at $12 \mathrm{~h}$ postcarboplatin was observed in the habenula perforata (Fig. 2B). Myelin sheaths were disrupted by large vacuoles containing myelin figures and calpain IR. Unlike the fine granular reaction product observed in the nerve fibers within the spiral ganglion (Fig. 2A), the reaction product in nerve fibers passing through the habenula perforata was typically dense and confined to large vacuoles associated with the myelin sheaths. In the organ of Corti (Fig. 2C), efferent terminals appeared normal. Some afferent synapses beneath the IHCs were enlarged but intact. The bases of IHCs were often distorted by swollen afferent terminals, but no calpain IR was visible within or around the hair cells at this time.

At $24 \mathrm{~h}$, the number and size of vacuoles within the myelin surrounding the type I spiral ganglion cells and the peripheral processes of type I neurons had increased and there was some swelling of the neuron somata (data not shown). Increased swelling and vacuolization in the nerve fibers and occasional rupture of the plasma membrane were also observed. The myelin surrounding nerve fibers in the habenula was severely disrupted and myelin debris was dispersed throughout the habenula, but only sparse calpain IR was observed at this time (Fig. 3). In contrast to the dense reaction product observed at $12 \mathrm{~h}$ (Fig. 2B), the reaction product at $24 \mathrm{~h}$ consisted of fine granules, and these granules were dispersed primarily among the layers of unraveled myelin rather than confined within large vacuoles. In the organ of Corti, many afferent terminals had ruptured, distorting the basal pole of the IHCs; however, no calpain IR was observed inside any IHC or OHC (data not shown).

At $48 \mathrm{~h}$, the myelin of most type I neurons in the spiral ganglion was severely disrupted. Intramyelinic vacuoles resulting from splitting of the myelin lamellae were commonly observed around type I ganglion cells (Fig. 4A). No calpain IR was observed inside any type I ganglion cell at this time. Strong calpain IR was present in the myelin surrounding the nerve fibers in the spiral ganglion, and numerous immunoreactive puncta were dispersed throughout the cytoplasm of some fibers. Most nerve fibers in the habenula perforata 


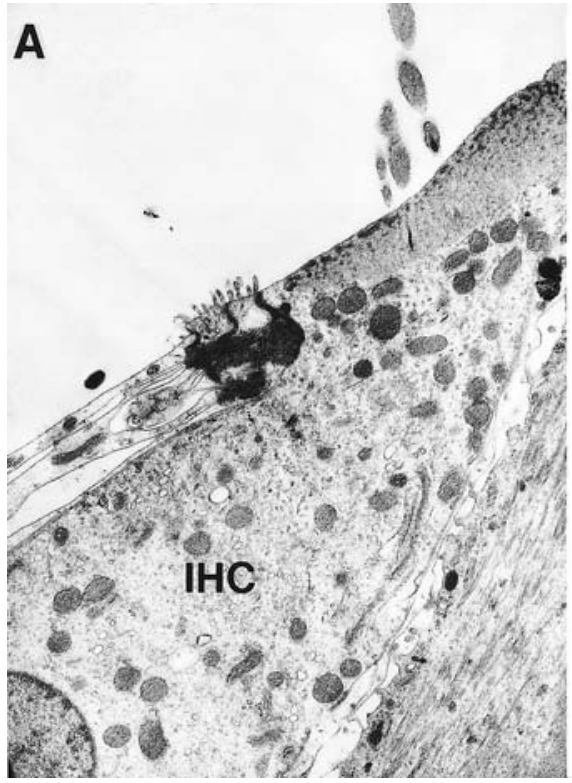

FIG. 1. Normal ears processed for calpain immunoreactivity (IR). A Normal inner hair cell (IHC) and supporting cell with normal mitochondria, intact membranes, and no calpain IR (original magnification $5000 \times$ ). B Normal nerve fiber (NF) passing through the habenula perforata of the osseous spiral lamina. Several fine granules of uniform darkness are present in the myelin sheath surrounding the
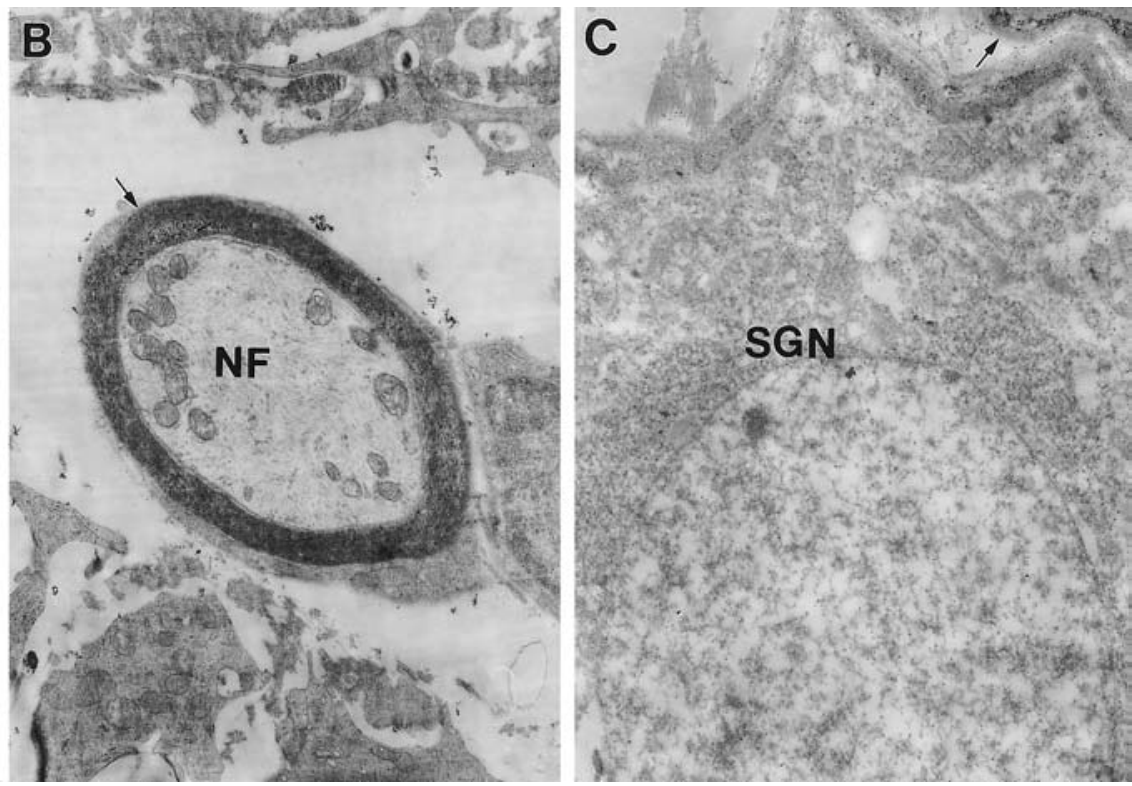

fiber (arrow), but all visible structures (myelin, fiber, mitochondria) appear morphologically normal (original magnification 8000×). C Normal spiral ganglion neuron (SGN) with no calpain IR in the nucleus or cytoplasm. However, several fine granules of uniform darkness (arrow) are seen in the myelin surrounding the neuron.
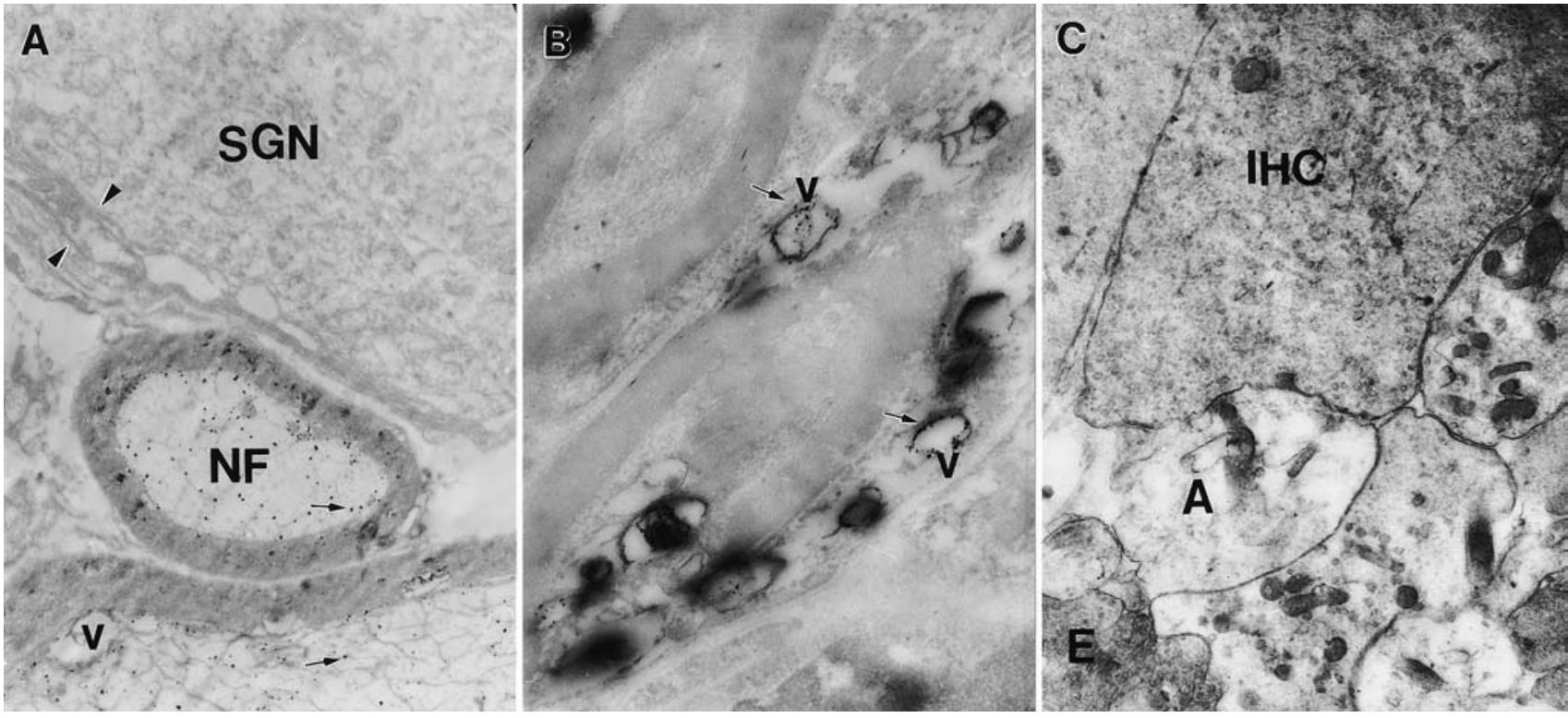

FIG. 2. Cochlear pathology and calpain IR $12 \mathrm{~h}$ after carboplatin. A Myelin in the spiral ganglion is split and edematous. Splitting and vacuolization are most prominent in the inner layers of myelin surrounding type I spiral ganglion cells (SGN) and nerve fibers (NF). Note the loop formed by the invagination of myelin into a vacuole (V) in a nerve fiber sheath. Numerous fine granular immunoreactive puncta (arrows) are dispersed throughout the cytoplasm of nerve fibers and within their myelin sheaths. However, no calpain IR is present within the cytoplasm or myelin of the type I ganglion cell adjacent to the nerve fiber, even in a region of myelin that is split (arrowheads) (original magnification 10,000×). B Calpain IR in the habenula perforata. Vacuoles ( $\mathrm{V}$, arrows) are found in myelin sheaths, inside nerve fibers, and in the Schwann cell processes surrounding them. Myelin figures and dense reaction product are present in most vacuoles (original magnification 20,000×). C The base of an inner hair cell (IHC) is distorted by swollen afferent terminals (A), but no calpain IR is visible within or around the hair cell at this time. Efferent terminals (E) appear normal (original magnification 10,000×). 


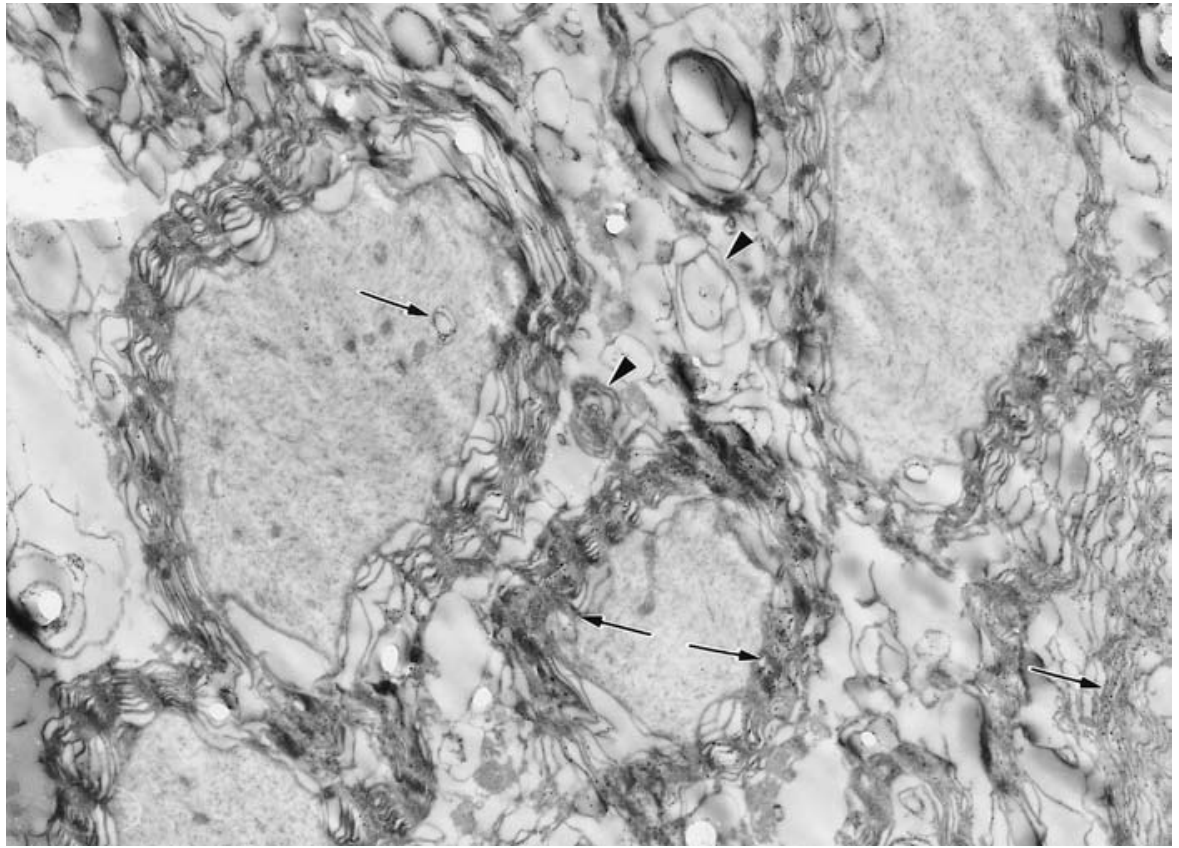

FIG. 3. Cochlear pathology and calpain IR in the habenula perforata $24 \mathrm{~h}$ after carboplatin. The myelin sheaths of nerve fibers are severely disrupted and myelin debris (arrowhead) is abundant in spaces between fibers. Fine granular immunoreactive puncta are associated with unraveled myelin and intramyelinic vacuoles (arrows) (original magnification $6700 \times$ ).
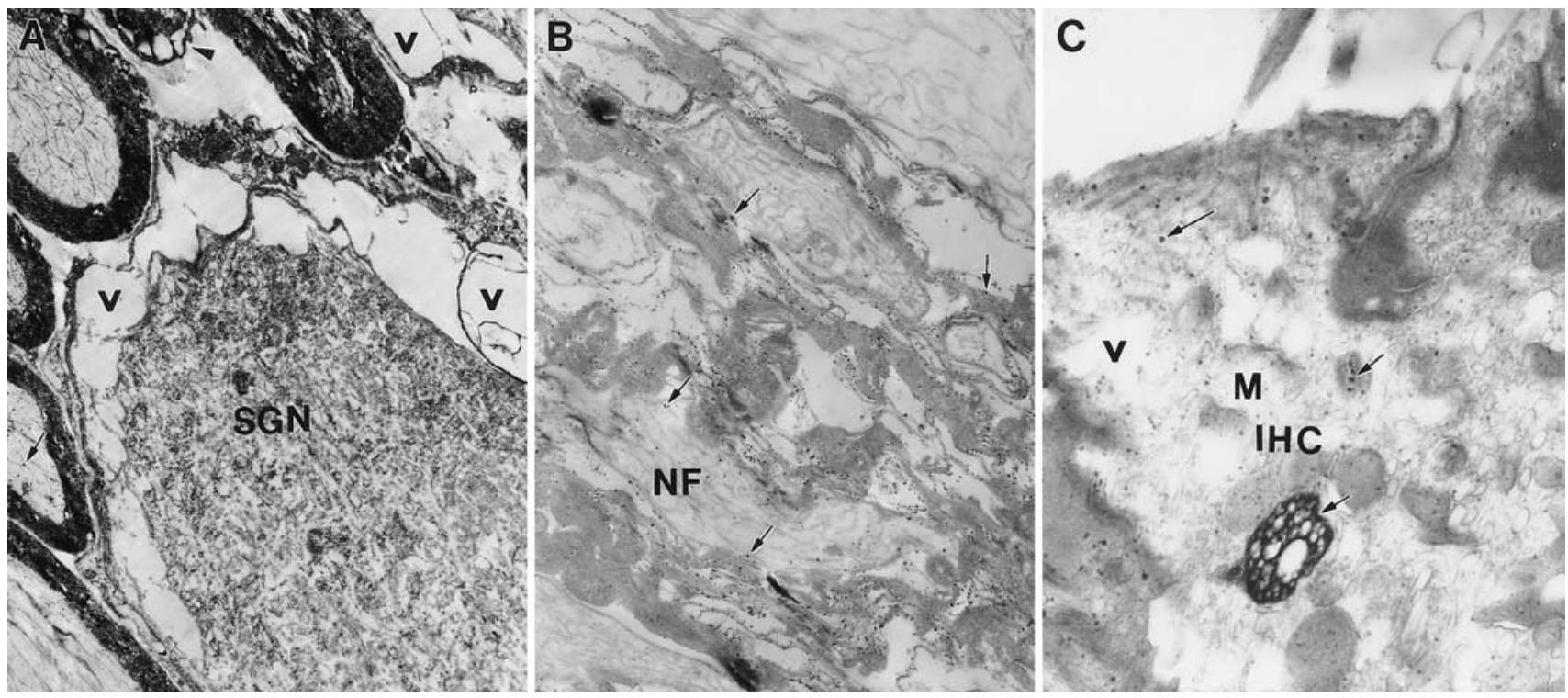

FIG. 4. Cochlear pathology and calpain IR $48 \mathrm{~h}$ after carboplatin. A Myelin and nerve fiber damage in the spiral ganglion is severe. The myelin surrounding the type I ganglion cell (SGN) is severely disrupted by edema, splitting, and vacuolization (V). However, no calpain IR is visible in the cytoplasm of the cell. Immunoreactive puncta (arrows) are dispersed throughout the cytoplasm of some nerve fibers, and strong immunoreactivity is associated with their myelin sheaths and intramyelinic vacuoles (arrowheads) (original magnifica-

were abnormal or destroyed, and the spaces were filled with debris and fine granular immunoreactive puncta (Fig. 4B). Calpain IR was observed inside one IHC and its supporting cells at $48 \mathrm{~h}$ postcarboplatin. As shown in Figure 4C, immunoreactive puncta were dis- tion $4000 \times)$. B The habenula is filled with debris and sparse fine granular immunoreactive puncta (arrows). Note abnormal nerve fibers (NF) (original magnification $8000 \times$ ). C Calpain IR inside an inner hair cell (IHC) and adjacent inner pillar cell. Calpain IR is present in the cuticular plate and in some disrupted mitochondria (M). Extensive vacuolization (V) gives the cytoplasm a spongiform appearance (original magnification $14,000 \times$ ).

persed through the cytoplasm of this cell, and the cytoplasm had a spongiform appearance due to the presence of numerous empty vacuoles.

At $72 \mathrm{~h}$, some ganglion neurons and IHCs appeared to be undergoing autolysis, and most nerve fibers in 


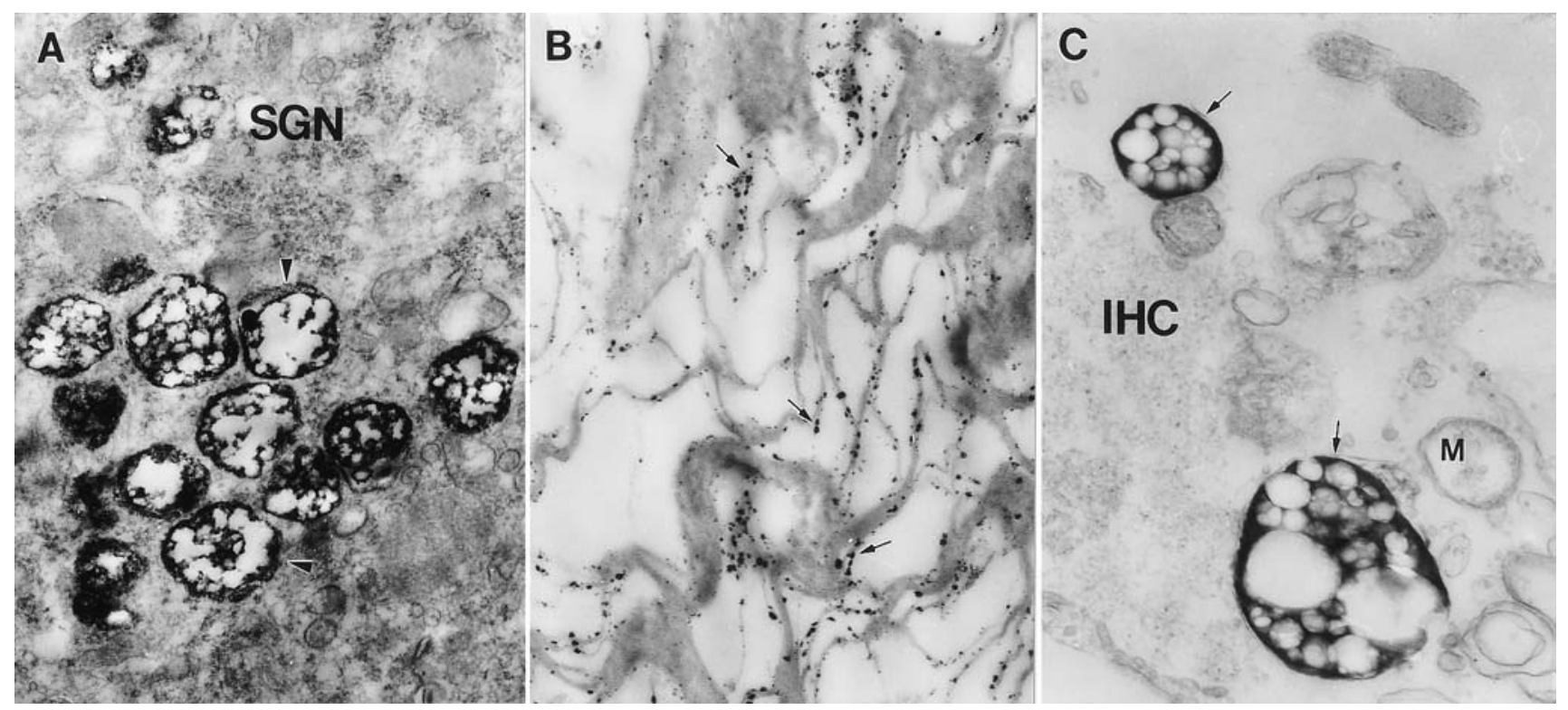

FIG. 5. Cochlear pathology and calpain IR $72 \mathrm{~h}$ after carboplatin. A Clusters of vacuoles (arrowheads) filled with dense reaction product in the cytoplasm of a type I spiral ganglion neuron (SGN) that is undergoing autolysis. Note loss of membranous infoldings in most mitochondria (original magnification 14,000×). B Granular immunoreactive puncta (arrowheads) are dispersed throughout the unraveled

the habenula perforata were destroyed. Clusters of vacuoles containing dense reaction product were observed in the cytoplasm of type I spiral ganglion neurons (Fig. 5A), and granular immunoreactive puncta were dispersed throughout the debris in the habenula (Fig. 5B). Calpain IR could be observed in many IHCs but in no OHCs at this time. In several IHCs undergoing autolysis, large vacuoles were associated with intense calpain IR (Fig. 5C).

Morphological damage in the cochlea was quantified by counting the number of nerve fibers within the habenula perforata and the number of missing hair cells in the organ of Corti at 24, 48, and $72 \mathrm{~h}$ postcarboplatin. Nerve fiber and hair cell losses are compared in Figure 6. There were 74.2 \pm 6.6 (mean $\pm \mathrm{SD}$ ) nerve fibers per habenula in normal ears. This number decreased to $37.15 \pm 7.5$ at $24 \mathrm{~h}$ postcarboplatin, representing a loss of approximately $50 \%$. Nerve fibers continued to degenerate, with counts of $27.70 \pm 6.3$ fibers/habenula at $48 \mathrm{~h}$ and $15.70 \pm 4.3$ fibers/habenula at $72 \mathrm{~h}$. In contrast to the early loss of nerve fibers, hair cell counts remained normal until $72 \mathrm{~h}$ postcarboplatin, when approximately $20 \%$ of IHCs were missing. OHC counts were normal at $72 \mathrm{~h}$.

\section{Calpain immunoreactivity and morphological damage in the vestibular system}

The data presented here show the pattern of calpain IR in the vestibular system after carboplatin. A detailed layers of myelin in the habenula (original magnification $27,000 \times$ ). C Intense calpain IR and large cytoplasmic vacuoles in remnant of an inner hair cell (IHC) in an advanced stage of autolysis. Note damaged mitochondria $(\mathrm{M})$ and the absence of a plasma membrane (original magnification $20,000 \times$ ).

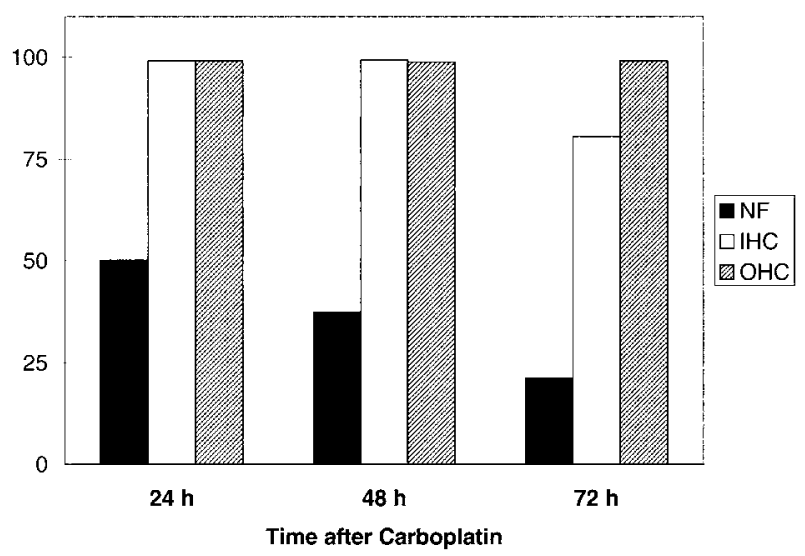

FIG. 6. Nerve fiber and hair cell losses at 24,48 , and $72 \mathrm{~h}$ postcarboplatin, expressed as percent missing relative to normal ears (see text for normal values).

description of the morphological damage in the vestibular system can be found in an earlier publication (Ding et al. 1997).

Calpain IR was observed in the nerve fibers and myelin in all vestibular end organs (both maculae and three ampullae) $12 \mathrm{~h}$ after carboplatin. The afferent dendrites beneath the type I hair cells in the maculae of the utricle were swollen, and the chalice contained numerous vacuoles and immunoreactive puncta that were remarkably uniform in size but variable in optical density (Fig. 7). Many mitochondria in the afferent dendrites and hair cells contained vacuoles as a result 


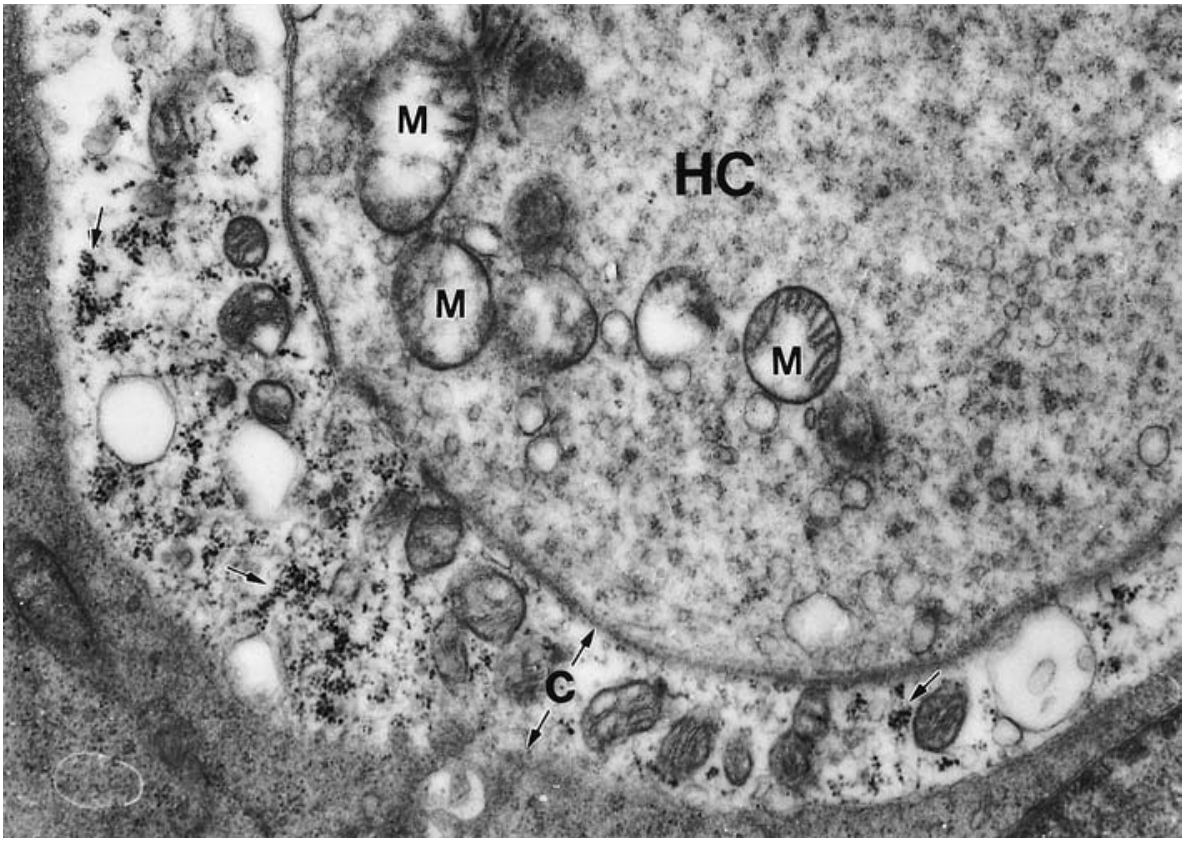

FIG. 7. Vestibular damage and calpain IR $12 \mathrm{~h}$ after carboplatin. Numerous vacuoles and immunoreactive puncta of uniform size but variable density (arrows) are present in the chalice $(\mathrm{C}$; width denoted by line with two arrowheads) beneath a type I hair cell (HC). No calpain IR is visible within the hair cell itself. Many mitochondria (M) show a loss of membranous infoldings (original magnification $14,000 \times)$. of the loss of membranous infoldings. No calpain IR was evident in the cytoplasm of type I hair cells or vestibular ganglion neuron somata at this time.

At $24 \mathrm{~h}$, vestibular ganglion neurons were slightly swollen but intact and devoid of calpain IR (data not shown). Strong calpain immunoreactivity was present in the disrupted myelin of vestibular nerve fibers, and scattered immunoreactive puncta were visible in the nerve fiber cytoplasm (Fig. 8A). Swollen vacuous mitochondria were present in the enlarged chalice region beneath type I hair cells with ruptured membranes (Fig. 8B). Calpain IR could be distinguished around and sometimes within the swollen mitochondria. Some calpain IR was observed in the cytoplasm of a few type I hair cells, but this was not a prominent feature.

The myelin of vestibular ganglion cells was severely disrupted at $48 \mathrm{~h}$. Myelin sheaths surrounding ganglion cells were separated from the cell membrane at the intraperiod line, creating large empty spaces (Fig. 9A). Strong calpain IR was observed in the myelin sheaths of nerve fibers adjacent to ganglion cell somata, and immunoreactive puncta were dispersed throughout the cytoplasm of the nerve fibers in the vestibular ganglion (Fig. 9A). Intramyelinic edema and vacuolization were prominent in the myelin surrounding vestibular nerve fibers, and fine granular immunoreactive puncta were dispersed among the myelin lamellae and in a few cytoplasmic vacuoles (Fig. 9B). A few immunoreactive figures were present in some damaged type I hair cells. However, calpain immunoreactivity was not a prominent feature of vestibular hair cells, even those undergoing autolysis (Fig. 9C).

Many of the type I hair cells were in a state of advanced degeneration at $72 \mathrm{~h}$ postcarboplatin. However, there was little calpain IR in the cytoplasm of the type I hair cells undergoing autolysis. The nerve fibers near the sensory hair cells were completely destroyed. Vacuoles lined with dense reaction product and containing immunolabeled debris were present in the cytoplasm of some vestibular ganglion neurons (Fig. $10)$.

\section{DISCUSSION}

The data reveal a sequence of carboplatin-induced pathology in the inner ear that starts with nerve fibers and myelin, progresses to involve type I hair cells and IHCs, and finally involves ganglion cell somata. The morphological damage to nerve fibers and their myelin sheaths was associated with increased calpain immunoreactivity. This study is the first to identify myelinopathy as a primary feature of carboplatin ototoxicity in the chinchilla and to show a link between calpain IR and carboplatin-induced inner ear damage.

\section{Significance of calpain immunoreactivity}

The location and time course of calpain IR support a role of calcium-dependent proteases in the destruction of nerve fibers and myelin, but not hair cells, after treatment with carboplatin. A destructive role of calpain in carboplatin ototoxicity is consistent with its known proteolytic activities. As reviewed by Goll et al. (1992) and Bartus (1997), calpain can activate or alter enzymes such as protein kinase $\mathrm{C}$ and phospholipase 


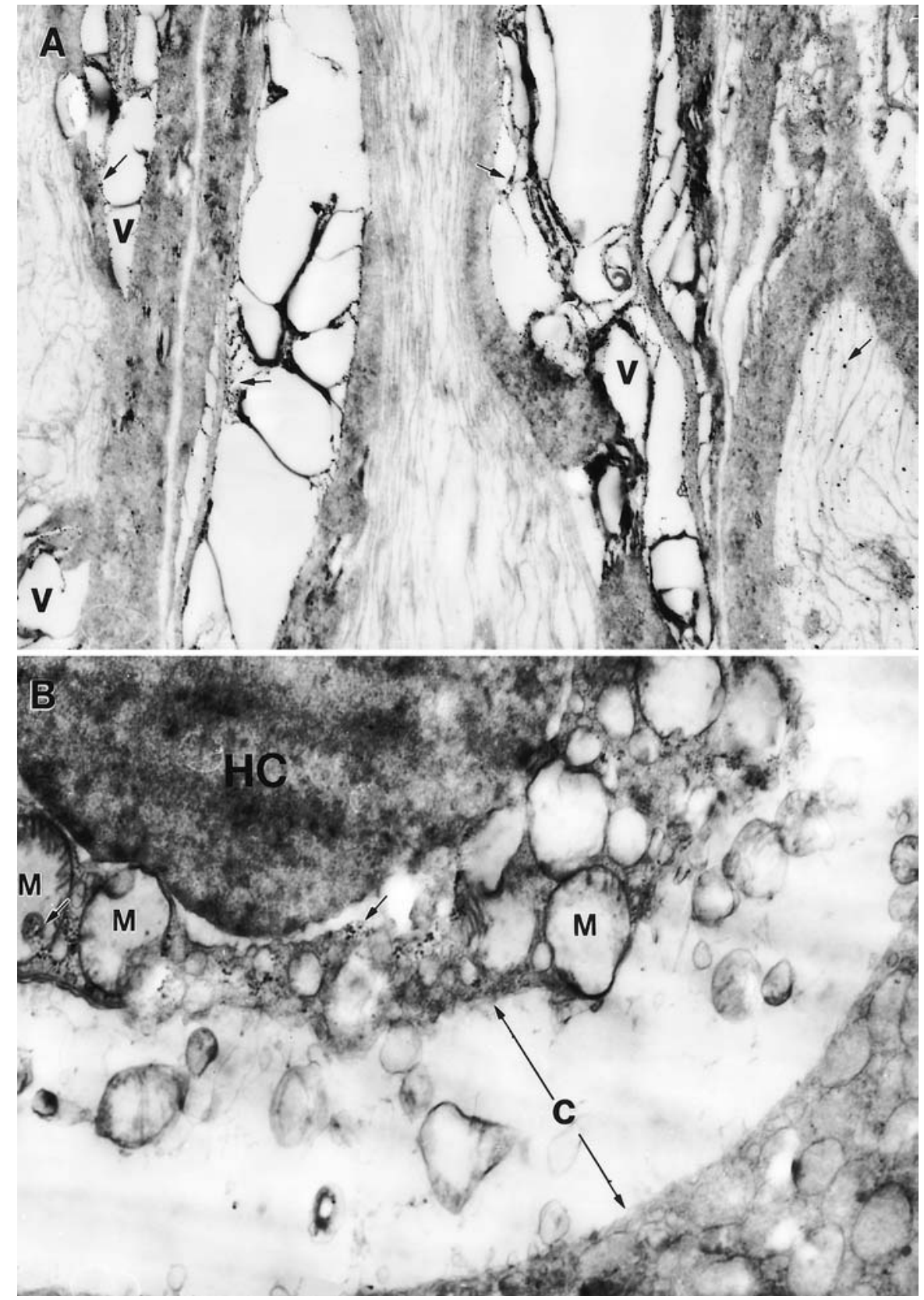

FIG. 8. Vestibular damage and calpain IR $24 \mathrm{~h}$ after carboplatin. A Strong calpain IR in the disrupted myelin and vacuoles (V) of vestibular nerve fibers. Note the presence of fine granular immunoreactive puncta (arrows) in the nerve fiber cytoplasm (arrow at far right) (original magnification 10,000×). B Abnormal mitochondria and numerous vacuoles are present at the base of a type I hair cell (HC). Because the plasma membrane of the hair cell has disintegrated, it is difficult to distinguish between the cell body and the chalice $(\mathrm{C}$; region between arrows). Immunoreactive puncta can be distinguished around the swollen mitochondria $(M)$ in the chalice region. Little or no calpain IR is discernible in the cytoplasm of the hair cell (original magnification $14,000 \times$ ).
C, cleave hormone receptors, and remodel or disassemble proteins, including cytoskeletal proteins (e.g., MAP 2, spectrin, tubulin, and neurofilament proteins) and myelin proteins (e.g., myelin basic protein and myelin-associated glycoprotein). Calpain proteolysis may therefore compromise the integrity of phospholipid membranes and cytoskeletal proteins, disrupt cellular transport mechanisms, degrade myelin, and impair cell signaling mechanisms. The ability of various calpain inhibitors, such as leupeptin, to reduce cell damage associated with noise exposure (Wang et al. 1999) and a wide variety of neurodegenerative conditions (Bartus 1997; Bartus et al. 1995; Stracher 1997) is compelling evidence of calpain's destructive potential.

The current data establish a relationship between calpain immunoreactivity and morphological damage in the chinchilla inner ear. Although we have no direct evidence that calpain caused morphological damage to nerve fibers and their myelin, several indirect lines of evidence support this interpretation. The earliest signs of damage in nerve fibers and their myelin sheaths coincided with increased calpain IR. In the habenula perforata, severe disruption of myelin at $24 \mathrm{~h}$ (Fig. 3) was preceded by the appearance of dense calpain IR in vacoules at $12 \mathrm{~h}$ (Fig. 2B). Increased proteinase 


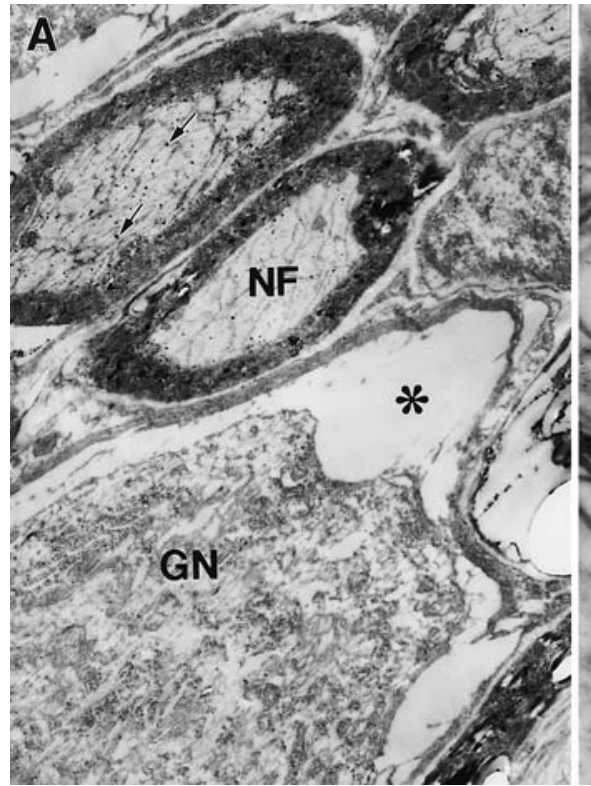

FIG. 9. Vestibular damage and calpain IR $48 \mathrm{~h}$ after carboplatin. A The myelin sheath surrounding a type I ganglion neuron $(G N)$ is separated from the cell membrane, creating large empty spaces (asterisks). No calpain IR is visible in the ganglion cell soma. Reaction product (arrows) is present in the myelin sheaths of nerve fibers adjacent to ganglion cell somata and dispersed throughout the nerve fiber (NF) cytoplasm (original magnification 6700×). B Intramyelinic edema and vacuolization in the myelin surrounding vestibular nerve fibers. Fine granular immunoreactive puncta (arrows) are visible between myelin lamellae and in a few cytoplasmic vacuoles (original magnification 20,000×). C A severely damaged type I hair cell (HC) shows little calpain IR. Afferent chalice (C between arrows) is swollen (original magnification $8000 \times$ ).

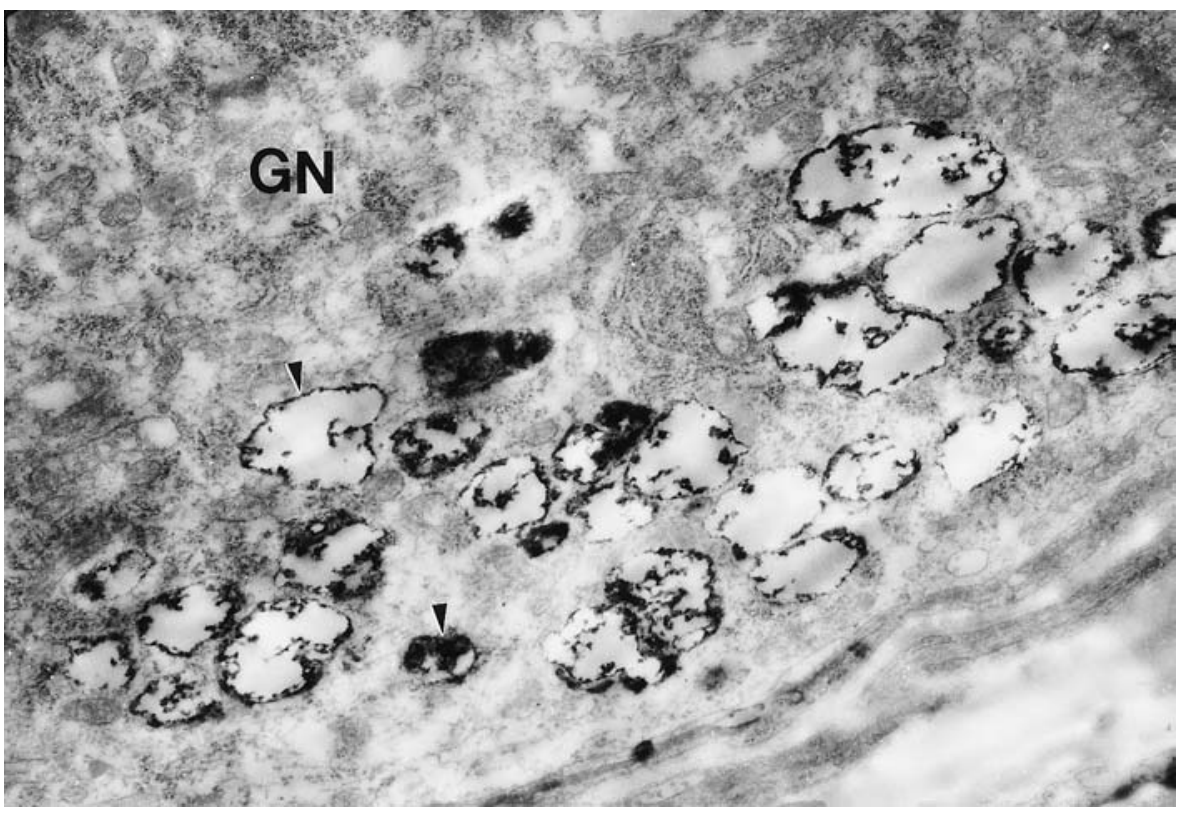

FIG. 10. Vacuoles in the cytoplasm of a type I vestibular ganglion neuron (GN) are lined with dense reaction product and contain immunolabeled debris (arrowheads). Cell features and boundaries are indistinct due to advanced degeneration (original magnification $14,000 \times$ ). activity that promotes the breakdown of myelin basic protein is thought to be an initial step in several demyelinating diseases (Banik et al. 1985). Banik et al. (1985) demonstrated that myelin-associated calpain is involved in the breakdown of myelin basic protein and proteolipid protein, and that the degradation of endogenous myelin proteins can be inhibited by leupeptin. Calpain has been implicated in myelin destruction during optic neuritis in rats (Shields and Banik 1998; Shields et al. 1998). Calpain inhibitors provided significant protection against axonal degeneration after traumatic spinal cord injury (Bartus 1997). Since 
myelin contains both calcium and calpain (Jortner 2000), a reasonable hypothesis is that carboplatin disrupts fluid balance in myelin, leading to elevated levels of intra- and extracellular calcium that induces proteolysis.

In contrast of a potential role of calpain in the destruction of nerve fibers and myelin, there is little evidence from our data that calpain is involved in carboplatin-induced hair cell loss or ganglion cell death. First, calpain IR did not coincide with the onset of damage in these cells. Second, although calpain IR was present in some IHCs, type I hair cells, and ganglion cells at $48-72 \mathrm{~h}$ postcarboplatin, labeling was relatively sparse and weak, even in cells that were clearly undergoing autolysis. Thus, it appears that cell death and ganglion cell death occur without significant calpain involvement. Third, a previous set of experiments from our lab (Wang et al. 1999) implicated calpain proteolysis in noise-induced OHC loss but not in carboplatin-induced IHC loss. In that study, leupeptin was infused into the right ears of chinchillas, while left ears served as controls. In one experiment, chinchillas were exposed to traumatizing noise for 48 h. Intense calpain IR was present in and around OHCs after noise exposure, and leupeptin provided significant (up to 60\%) protection of OHCs. In the companion experiment, chinchillas received leupeptin beginning four days prior to carboplatin. When hair cell loss was determined one month later, the pattern and magnitude of IHC loss was very similar between leupeptin-treated ears $(48 \% \pm 32)$ and control ears $(48 \% \pm 17)$. The inability of leupeptin to protect IHCs from carboplatin is consistent with the current results showing weak calpain IR in IHCs only during the final stages of their degeneration. Interestingly, leupeptin was recently found to be ineffective in protecting auditory hair cells and spiral ganglion neurons from cisplatin-induced damage in culture (Cheng et al. 1999). Taken together, the data suggest that the death of IHCs and ganglion cells is triggered by mechanisms other than calpain activation. It will be interesting in future studies to see if leupeptin can protect nerve fibers and myelin from damage in preparations from adult animals in which myelin is present.

One hypothesis to account for an involvement of calpain in the destruction of nerve fibers and their myelin, but not IHCs or ganglion cells, is related to the timing and magnitude of calpain activation. Calpain might trigger cell death mechanisms only after some threshold level of activation has been reached. In low quantities, calpain may participate in processes aimed at repair and recovery rather than destruction, as suggested by several recent studies. Faddis et al. (1997) produced sublethal injury in cultured cortical neurons by exposing them to a glutamate receptor agonist. Surprisingly, calpain inhibitors impeded spontaneous recovery of dendrites. Brana et al. (1999) found that a calpain inhibitor could have either protective or toxic consequences on ischemic damage to cultured hippocampus cells depending on when it is applied. Although the current data support a direct role of calpain in the destruction of nerve fibers and myelin and a nondestructive role of calpain in hair cells and ganglion cells, further studies are required to understand the physiological significance of calpain in the inner ear.

Myelinopathy and axonopathy are primary features of carboplatin ototoxicity in chinchilla

Morphological damage and increased calpain immunoreactivity were seen first in nerve fibers and their myelin sheaths. Peripheral sensory neuropathy due to axonal degeneration and myelin breakdown is not uncommon in humans receiving high doses of cisplatin (Roelofs et al. 1984; Thompson et al. 1984). Roelofs et al. (1984) reported that $92 \%$ of their patients treated with cisplatin developed signs and symptoms of sensory peripheral neuropathy. Sural nerve biopsies in several patients confirmed axonal and myelin degeneration. Thompson et al. (1984) argued that the primary damage from cisplatin is to the axon, with secondary breakdown of myelin. In our material, however, axonopathy and myelinopathy occurred early in the degenerative process, but they appeared to be independent events. Cases in which damaged myelin surrounded normal nerve fibers and cases in which damaged nerve fibers were ensheathed by intact myelin were both observed.

Myelinopathy and axonopathy similar to that caused by carboplatin in the present study are features associated with other exogenous toxins (e.g., chronic dietary copper poisoning, triethyltin, tellurium, hexachlorophene) and some demyelinating diseases. Interestingly, many of the agents that produce intramyelinic vacuoles similar to those seen in the present study are known to uncouple oxidative phosphorylation in mitochondria (Obermaier et al. 1995). Because morphological similarities could point to common underlying mechanisms, it may be worthwhile to consider two other metal-induced myelinopathies here.

Triethyltin poisoning in rabbits produces a similar myelinopathy to that seen here, in which large clefts and vacuoles are enclosed or lined by layers of myelin (Aleu et al. 1963). The myelin surrounding the vacuoles was generally intact, even when it was markedly elongated to surround large, irregular spaces. Myelin splits and edema were observed in all poisoned animals. The route by which fluid entered the spaces was not evident, but Aleu et al. (1963) suggested that myelin breakdown altered the osmotic conditions to 
such an extent that water and electrolytes were drawn in to form the vacuoles. Similar processes could contribute to intramyelinic edema from carboplatin. Interestingly, triethyltin and trimethyltin have been found to induce hearing loss (Besser et al. 1987) and rapid deterioration of the auditory nerve compound action potential, suggesting early damage to neurons or the afferent synapse. The cochlear microphonic potential was normal, suggesting normal $\mathrm{OHC}$ function (Clerici et al. 1991). Histological analysis revealed OHC loss at $48 \mathrm{~h}$ post-treatment (Hoeffding and Fechter 1991). Damage at longer survival times was more extensive and involved IHCs and type I spiral ganglion neurons.

Another heavy metal, tellurium, damages Schwann cells and inhibits cholesterol synthesis, which leads to destabilization of formed myelin (Jortner 2000). The affected myelin bubbles or unravels as a result of loosening of lamellae and intramyelinic edema and splitting of intraperiod and major dense lines. This produces an appearance similar to that observed in the present study. It has been suggested that the presence of abnormal membrane-lined vacuoles in axons and/ or their myelin sheaths may represent a "chemical transection" of the fiber that leads to its degeneration (Jortner 2000). Since the cell body is generally intact, axonal regeneration may be possible.

The present data show that carboplatin-induced axonopathy and myelinopathy are correlated with calpain immunoreactivity. The antibody we used reacts with the small regulatory subunit that is common to tissue-specific forms of calpain (e.g., calpain P94 and NCL2) as well as to the ubiquitous forms, calpain I ( $\mu$ calpain) and calpain II (m-calpain). Thus, the specific identity of the activated protease(s), as well as their actual functions, remain to be determined.

\section{ACKNOWLEDGMENT}

This work was supported by NIDCD grant P01 DC0360001A1 (RJS and SLM).

\section{REFERENCES}

AGGARWAL SK. A histochemical approach to the mechanism of action of cisplatin and its analogues. J. Histochem. Cytochem. 41:10531073, 1993.

Aleu FP, Katzman R, Terry RD. Fine structure and electrolyte analyses of cerebral edema induced by alkyl tin intoxication. J. Neuropathol. Exp. Neurol. 22:403-413, 1963.

Banik NL, MCAlHaneyWW, Hogan EL. Calcium-stimulated proteolysis in myelin: evidence for a $\mathrm{Ca}^{2+}$-activated neutral proteinase associated with purified myelin of rat CNS. J. Neurochem. 45:581588, 1985 .

Bartus RT, Elliott PJ, Hayward NJ, Dean RL, Harbeson S, Straub JA, LI Z, Powers JC. Calpain as a novel target for treating acute neurodegenerative disorders. Neurol. Res. 17:249-258, 1995.
BARTUS RT, The calpain hypothesis of neurodegeneration: Evidence for a common cytotoxic pathway. The Neurosci. 3:314-327, 1997. Besser R, Kramer G, Thumler R, Bohl J, Gutmann L, Hopf HC. Acute trimethyltin limbic-cerebellar syndrome. Neurology 37:945-950, 1987.

Brana C, Benham CD, SundSTRom L. Calpain activation and inhibition in organotypic rat hippocampal slice cultures deprived of oxygen and glucose. Eur. J. Neurosci. 11:2375-2384, 1999.

Cheng AG, Huang T, Stracher A, Kim A, Liu W, Malgrange B, Lefebvre PP, Schulman A, VAN DE Water TR. Calpain inhibitors protect auditory sensory cells from hypoxia and neurotrophinwithdrawal induced apoptosis. Brain Res. 850:234-243, 1999.

Clerici WJ, Ross B JR, Fechter LD. Acute ototoxicity of trialkyltins in the guinea pig. Toxicol. Appl. Pharmacol. 109:547-556, 1991.

DING D, WANG J, SALVI RJ. Early damage in the chinchilla vestibular sensory epithelium from carboplatin. Audiol. Neurootol. 2:155$167,1997$.

Ding D, WANG J, Zheng XY, SAlvi RJ. Histochemical changes in the cochlea of chinchillas with carboplatin induced inner hair cell loss. Abstr. Assoc. Res. Otolaryngol. 613:155, 1999a.

Ding DL, Wang J, Salvi R, Henderson D, Hu BH, McFadden SL, MUELLER M. Selective loss of inner hair cells and type-I ganglion neurons in carboplatin-treated chinchillas. Mechanisms of damage and protection. Ann. N. Y. Acad. Sci. 884:152-170, 1999b.

FADDIS BT, HASBANI MJ, GOLdBERG MP. Calpain activation contributes to dendritic remodeling after brief excitotoxic injury in vitro. J. Neurosci. 17:951-959, 1997.

Gemba M, Nakatani E, Teramoto M, Nakano S. Effect of cisplatin on calcium uptake by rat kidney cortical mitochondria. Toxicol. Lett. 38:291-297, 1987.

GO RS, ADJEI AA. Review of the comparative pharmacology and clinical activity of cisplatin and carboplatin. J. Clin. Oncol. 17:409422, 1999.

GOLL DE, ThOMPSON VF, TAYLOR RG, ZALEWSKA T. Is calpain activity regulated by membranes and autolysis or by calcium and calpastatin? BioEssays 14:549-556, 1992.

HOEFFding V, FeCHTER LD. Trimethyltin disrupts auditory function and cochlear morphology in pigmented rats. Neurotoxicol. Teratol. 13:135-145, 1991.

Hofstetter P, Ding D, Powers N, SAlvi RJ. Quantitative relationship of carboplatin dose to magnitude of inner and outer hair cell loss and the reduction in distortion product otoacoustic emission amplitude in chinchillas. Hear. Res. 112:199-215, 1997a.

Hofstetter P, Ding D, SAlvi R. Magnitude and pattern of inner and outer hair cell loss in chinchilla as a function of carboplatin dose. Audiology 36:301-311, 1997b.

JORTNER BS. Mechanisms of toxic injury in the peripheral nervous system: neuropathologic considerations. Toxicol. Pathol. 28:5469, 2000.

Lee MS, Kwon YT, Li M, Peng J, Friedlander RM, Tsai LH. Neurotoxicity induces cleavage of p35 to p25 by calpain. Nature 405:360364, 2000.

Mount RJ, Takeno S, Wake M, Harrison RV. Carboplatin ototoxicity in the chinchilla: lesions of the vestibular sensory epithelium. Acta Otolaryngol. Suppl. 519:60-65, 1995.

Obermaier G, Kretzschmar HA, Hafner A, Heubeck D, Dahme E. Spongiform central nervous system myelinopathy in African dwarf goats. J. Comp. Pathol. 113:357-372, 1995.

Piccart MJ, Nogaret JM, Marcelis L, Longree H, Ries F, Kains JP, Gobert P, Domange AM, Sculier JP, Gompel C. Cisplatin combined with carboplatin: a new way of intensification of platinum dose in the treatment of advanced ovarian cancer. Belgian Study Group for Ovarian Carcinoma. J. Natl. Cancer Inst. 82:703707, 1990.

REEDIJK J. Medicinal applications of heavy-metal compounds. Curr. Opin. Chem. Biol. 3:236-240, 1999. 
Roelofs RI, Hrushesky W, Rogin J, Rosenberg L. Peripheral sensory neuropathy and cisplatin chemotherapy. Neurology 34:934938, 1984.

SCHWEITZER VG. Ototoxicity of chemotherapeutic agents. Otolaryngol. Clin. North Am. 26:759-789, 1993.

SHIELDS DC, BANIK NL. Putative role of calpain in the pathophysiology of experimental optic neuritis. Exp. Eye Res. 67:403-410, 1998.

Shields DC, Tylor WR, Deibler GE, BANIK NL. Increased calpain expression in experimental demyelinating optic neuritis: an immunocytochemical study. Brain Res. 784:299-304, 1998.

STRACHER A. Calpain inhibitors as neuroprotective agents in neurodegenerative disorders. Int. Tinnitus J. 3:71-75, 1997.

Takeno S, Harrison RV, Ibrahim D, WAKe M, Mount RJ. Cochlear function after selective inner hair cell degeneration induced by carboplatin. Hear. Res. 75:93-102, 1994a.

Takeno S, Harrison RV, Mount RJ, WaKe M, Harada Y. Induction of selective inner hair cell damage by carboplatin. Scanning Microsc. 8:97-106, 1994b.

Thompson SW, Davis LE, Kornfeld M, Hilgers RD, Standefer JC. Cisplatin neuropathy. Clinical, electrophysiologic, morphologic, and toxicologic studies. Cancer 54:1269-1275, 1984.

Trautwein P, Hofstetter P, Wang J, Salvi R, Nostrant A. Selective inner hair cell loss does not alter distortion product otoacoustic emissions. Hear. Res. 96:71-82, 1996.

WAKE M, TAKENO S, IBRAHIM D, HARRISON R. Selective inner hair cell ototoxicity induced by carboplatin. Laryngoscopy 104:488493, 1994.

Wang J, Ding D, Shulman A, Stracher A, Salvi RJ. Leupeptin protects sensory hair cells from acoustic trauma. Neuroreport 10:811-816, 1999.

YAMASHIMA T. Implication of cysteine proteases calpain, cathepsin and caspase in ischemic neuronal death of primates. Prog. Neurobiol. 62:273-295, 2000. 